\title{
An education revolution in response to the longevity revolution
}

Alexandre Kalache' $\mathbb{D}$

It is increasingly argued that the most consequential legacy of the past century is the gift of longer life. Currently, two people in the world reach their $60^{\text {th }}$ birthday every second ${ }^{1}$. By 2050, the 60-plus age group will constitute $30 \%$ of the populations in 64 countries ${ }^{1}$. Almost all developed countries will be on that list but so too will be most of Latin America, the Caribbean and large parts of Asia, including China ${ }^{1}$. By this time, the over 60s will form a worldwide bloc of more than 2 billion people that will outnumber those under 15 years of age ${ }^{2}$. Already, there are currently more people over the age of 60 than children below the age of five $e^{2}$. Reaching older age has ceased to be the privilege of the few and has become the realistic expectation of the many, in most regions of the world.

This longevity revolution forces us to totally rethink previously-held notions about ageing and older age. It has revealed to us that life is now more like a marathon than a 100-metre sprint. But it is a marathon with an indeterminate finish line that is run in a continuously changing landscape where there is a perpetual interplay between risk and opportunity. Ageing is a dynamic relational process. We are all unsteady travellers throughout the journey - buffeted daily by the conditions and the contradictions of our own histories. Our longer lives are increasingly being lived in the context of a barrage of disruptive changes that are upending our assumptions and undermining many of our skill sets. We are living longer but the relevance of much of our acquired knowledge is expiring earlier.

Parallel to the longevity revolution is a technology revolution characterised by an unprecedented hyper-connectivity between a vast range of previously

\footnotetext{
1 The International Longevity Centres - Global Alliance (ILC-GA) and The International Longevity Centre - Brazil (ILC-BR). London, UK.
}

The authors declare there are no conflicts of interest in relation to the present study.

No funding was received in relation to the present study. 
segregated components. This fusion reaches across all digital, physical and biological domains to create a complex and extraordinary web. This so-called Fourth Industrial Revolution is "the inexorable shift from the simple digitalisation that characterised the Third Industrial Revolution to a much more complex form of innovation based on the combination of multiple technologies in novel ways" ${ }^{3}$. It is a fastmoving revolution with very pronounced human repercussions - such as increased job insecurity; a growing need for multiple identities; an imposed mobility; and an uneven ownership of the new technologies.

Debate about the future impacts of the Fourth Industrial Revolution is on-going. A much referenced Oxford University study predicted that almost half of all present-day jobs are at high risk over the next two decades ${ }^{4}$. Other studies suggest a much lower risk of the wholesale displacement of jobs yet nevertheless warn that a likely majority of occupations will be radically redefined through new technologies ${ }^{5}$. The OECD estimates that an average of only $9 \%$ of jobs are at risk of total disappearance but predict that between $50-70 \%$ of all jobs will be radically transformed ${ }^{5}$. It is suggested that as many as sixty percent of the jobs that will be performed by the next generation do not yet even exist ${ }^{6}$. It is clear that the educational assets acquired in youth and early adulthood no longer provide sufficient currency for longer, big change impacted lives.

The powerful synergy of the Longevity Revolution and the Fourth Industrial Revolution necessitate a corresponding Education Revolution that structurally embeds a comprehensive culture of rights-based, life-long learning. At each stage of life, all individuals must gain a familiarity with the necessary intellectual and emotional tools for a rapidly evolving present and an unclear future. A fitfor-purpose 21st century architecture of inclusive, people-centred learning at all ages must go beyond a narrow focus on employment skills. The new model must strengthen health, technology, environmental, financial and citizenship literacy. It must value experience, metacognition and intuition. And, it must seek to enhance resilience, self-reflection and empathy.
Access to information, or content, is no longer the main driver of change. "Knowledge was the key asset for the $20^{\text {th }}$ century. Imagination is the key asset for the $21^{\mathrm{st}}$ ? 7 . Information is now instantly available at the fingertips. According to an FGV study, there were already 198 million smart phones in use in Brazil in 2017". "Favelados" may not have functioning sewerage systems but they have the same lens on the world as citizens of the developed world. Having information is now less of an issue than knowing what to do with that information. It is discernment and application of information that is now the main driver of change.

Universities all over the world are experiencing an existential crisis. Concerns about rising costs (outstanding student loan debt in the US now stands at 1.41 trillion dollars') are loudly voiced. Questions are raised about the value-for-money and the practical relevance of much of the offered study. Accusations of an inward-looking exclusivity are increasingly articulated. There are suspicions of a causal link between rising student debt and declining rates of entrepreneurship, particularly among the socalled millennials. Innovators such as Bill Gates (Microsoft); Steve Jobs (Apple); Mark Zuckerberg (Facebook); Michael Dell (Dell Computers); Larry Ellison (Oracle); and Travis Kalanick (Uber); famously dropped out of their respective universities. Controversial billionaire "disrupter" Peter Thiel (Pay Pal) is currently paying students to reject their universities in the belief that the institutions themselves actually hinder innovation. There are indications that more employers are now valuing such features as curiosity and adaptability over formal qualifications. Goggle and other tech giants no longer insist upon diplomas for employment at all. "If there were more disruption within the ivory tower, economies just might be more resilient to disruption outside it" ${ }^{\prime \prime 10}$.

The first conversations to define age-friendly environments took place at the World Health Organisation (WHO) in the 1990s. In 2007 the, Age-friendly Cities Guide, the founding document of the WHO Age-friendly Cities and Communities Network, was launched. It was called age-friendly and not old age or senior-friendly for a reason. Age- 
friendly is about optimising opportunities for health, life-long learning, participation and security as we age. The "as we age" is fundamental. Age-friendly was designed to be friendly to all ages. It is an obvious but neglected truth -that ageing is the one human experience that we all share - even if we do not share it on equal terms. There is no singular constituency for age-friendly. The sciences of physiology and psychology show us that the ageing journey up until our mid-twenties (when we reach the peak of our functional physical capacity) has different features from the ageing journey that we take beyond our mid-twenties. But it is the same journey. We do not become a different person as we age. We become more of the same person as we age.

Our longer lives are increasingly required to respond to a more complex range of intermingling and sometimes recurring variables. The boundaries of the traditional three stage life-course model (learning, working, retiring) are inevitably going to become even more blurred. Learning may continue to predominate in the first decades of life but it will not stop there. The OECD considers continuous learning to be one of the most important components of human capital in an ageing world ${ }^{11}$. According to UNESCO, it is "the key philosophy, conceptual framework and organising principle for education in the $21^{\text {st }}$ century" 12 and the United Nations regards it as a key priority issue in the global development agenda ${ }^{13}$. WHO takes the view that investment in education is also an investment in health and wellbeing $^{14}$. The International Labour Organisation (ILO) is calling for the formal recognition of a "universal entitlement to Lifelong Learning"15. Continuous in-job training, short courses, on-line tutorials and stackable diplomas to keep pace with the ever-more rapid changes in knowledge and technology will need to accompany people throughout the entirety of their lives. The trend toward extended working lives is likely to continue but more people will retire in a more gradual and individualised manner ${ }^{16}$. The sharing of family and home management duties within relationships will continue to be negotiated ${ }^{17}$. Some research in developed countries predicts that a more equal division between women and men in the home will evolve ${ }^{18}$. Individuals will learn, care, work and take leisure throughout their lives with much less attention to both social expectation and chronological age. As the borders to the different stages of life become more porous and variable, there will be less segregation of age groups. More generations, but fewer representatives of each, will be simultaneously present and engaging in society. Larger numbers of older and younger adults will contemporaneously share the same spaces and experiences - such as university classes, in-job training and leisure pursuits.

Individuals must adapt to these cultural shifts inherent within the longevity and technology revolutions - but so too must institutions. Furthermore, these institutions must be strategic. Many of the studies indicate that life-long learning as currently offered is inclined toward the already advantaged. Similar concerns have been expressed about many of the Age-friendly Cities and Communities initiatives. Those who could benefit the most tend to participate the least ${ }^{19}$, and participation tends to decrease with age $^{20}$. It is clear too, that the nature and application of the new technologies themselves are also reinforcing inequalities because they impact disproportionately. According to the OECD, $40 \%$ of workers with a lower secondary degree are in jobs with a high risk of displacement whereas less than $5 \%$ of workers with a tertiary degree are expected to face such a threat ${ }^{21}$.

Political disaffection from groups of people who feel marginalized is increasingly evident throughout the world. All educational institutions must play a role in the response to this alienation and an agefriendly educational approach must form part of the new paradigm. There must be a targeting of key demographics, such as men in blue-collar jobs, who are at the very highest risk from technological disruption. Imaginative retraining pathways must be established that counter this groups rejection of roles that are seen as less masculine, such as those found in fast-expanding areas such as health care. All training grounds, including universities, must focus on the widest possible range of learners (such as those emerging from care responsibilities or displaced occupational roles) and the enormous diversity of their needs. They must recognise that the new model must go far beyond any single institution, or even groups of institutions - that it must involve many partners and many routes (both formal and informal). Age-friendly learning 
institutions must tailor outreach to such bodies as employer associations, unions, technical colleges, job centres, prisons and seniors` organisations. They must offer the very broadest possible vision of a la carte, modular learning for all ages. They must also develop comparable levels of institutional awareness and self-regulation on ageism as many increasing do in relation to sexism and racism. In addition to their own staff and student bodies, they must embed an on-going dialogue about ageism with government, civil society organisations and the private sector. They must be alert to ageist attitudes in their employment practices, student induction and research agendas and extend an invitation to alumni and retired staff for stronger collaboration. They must embrace the full life-course and aim to build resilience and citizenship far beyond their traditional student base.

The longevity revolution is impacting virtually every aspect of human life yet our educational curricula still does not reflect this reality. Institutions are still training health professionals for the requirements of previous times - with an exaggerated emphasis on maternal and child health and an under-emphasis in all aspects related to ageing. (More than 100 countries now have total fertility rates at or below replacement level) ${ }^{22}$. Our architects, engineers, and urban planners are still leaving educational institutions without an informed understanding of the design requirements of an ageing population. Our business graduates, public administrators and future policy-makers are still woefully under-briefed about the demographic realities. All designers, whether of products, services or environments, need to be fully aware that every age-group is a rich and essential cultural reference ${ }^{23}$. For any teaching facility to claim age-friendliness there must be a commitment to mainstream ageing throughout its entire curricula. There is a need for more geriatricians and gerontologists but even more important is the need for all professionals, not only those in the health sector, to have an understanding of older age. Whether in service or product oriented fields, nearly all professionals are finding that an increasing proportion of their clients, customers and patients are older adults. This trend will continue.
The Longevity Revolution has engendered many predictions of dire economic and social consequences based on an assumption that older persons constitute a growing burden on the rest of society. The substantial and fast-moving demographic transitions do not signal macro-economic catastrophe but they do point to the need for an urgent re-evaluation of the life-course trajectory and older adulthood itself ${ }^{24}$. The gift of longer life is arguably the finest achievement of civilisation and it is generating almost limitless potential for overall human development. It is unimaginable that current and future generations will experience older age like their antecedents. In much the same way that the social construct of adolescence developed in the early to mid $20^{\text {th }}$ century, gerontolescence (is the period of early old age; a transitional phase between senior adulthood and more pronounced senescence. It is an emerging stage of human development that is still being defined by the first cohort of gerontolescents) - a contemporary transitional phase at the beginning of older adulthood that is delineated more by functional markers than chronological age - is now emerging in the $21^{\text {st }}$ century. It was the baby-boomers who defined the former in their youth and they are now defining the latter in the present. As gerontolescents, they are reinventing the way that older age is lived and viewed and humanity is forever different as a result.

It is the dynamic, life-long interplay of opportunity and risk, within both the person and the environment that informs the concept of Active Ageing. Both as an individual aspiration and a social policy framework, Active Ageing presents a roadmap toward resilience - defined as "baving access to the required reserves to adapt to, endure, or grow from the challenges encountered in life" 25 . It emphasises the need for continual adaptation and renewal. It facilitates the development of an individual resilience, of an active ageing throughout the life-course, but simultaneously stresses the importance of publicly coordinated efforts. Toward this end, Active Ageing offers a broad and integrative policy framework to all social institutions - one that opens spaces for individuals to seize opportunities over the full course of their lives and to establish a trajectory toward an improved well-being in older life. The framework stresses the critical importance of lifelong 
learning across all domains. It gives strong focus to health literacy ("gain access to, understand and use information in ways which promote and maintain good health" - WHO). in its widest possible sense and strives to achieve goals that are preventative, restorative and protective across a full range of capacity and resources.

Despite the promises of the new technological age, human capital remains society`s most valuable asset/renewable resource. Yet, according to the OECD, $31 \%$ of $15-19$ year olds and $71 \%$ of $20-24$ year olds in Brazil are not enrolled in education ${ }^{26}$. How will these individuals be integrated into the

\section{REFERENCES}

1. United Nations Population Fund. Ageing in the Twenty-First Century: a celebration and a challenge. New York: UNFPA/HelpAge International; 2012.

2. United Nations, Department of Economic and Social Affairs Population Division. World population prospects: the 2012 revision. Highlights and Advance Tables. New York: United Nations; 2013. Working Paper No. ESA/P/WP.228

3. Schwabb K. The Fourth industrial revolution. New York: World Economic Forum Publications; 2016.

4. Frey C, Osborne M. The Future of Employment: how susceptible are jobs to computerisation?.Oxford: University of Oxford, Oxford Martin School; 2013.

5. Organization for Economic Co-operation and Development. The Future of Work and Skills. In: 2nd Meeting of the G20 Employment Working Group; 1517 Feb. 2017; Hamburg. Hamburg: OECD, 2017.

6. Bris Arturo. The 2016 IMD World Talent Report. Switzerland: IMD; 2016.

7. Hilton A. How to Survive Work in the 21st Century. Evening Standard (London). 2016 Oct. 18. Sect. Business.

8. Meirelles F. Centro de Technologia de Aplicada. São Paulo: Fundacao Getulio Vargas; 2017.

9. New Zealand. Ministry of Education. The Student Loan Report. Wellington: ME; 2017.

10. Rogoff K. When Will Tech Disrupt Higher Education? Azernews (Baku). 2018 Feb. 07: Sect Analysis.

11. Keeley B. Insights-Human Capital: How what you know shapes your life. Paris: OECD Publishing; 2007. rapidly changing global labour force? What health behaviours will they employ throughout their life courses? What level of support will they be able to provide to their aged parents? What sort of older citizens will they themselves have become by 2060 ? And to what extent will their lack of skill preparedness for the new technological age continue to limit Brazil to the role of commodity exporter to the more sophisticated economies? It is incumbent upon every society to reinvent the culture of learning and to scrupulously mine the rich veins of all human capacity. As individuals, we must learn to learn and embrace our full citizenship in each of the transformative stages of the ageing continuum.

Edited by: Ana Carolina Lima Cavaletti

12. United Nations Educational Scientific and Cultural Organization. Institute for Life-long Learning [Internet]. Paris: UNESCO; 2017 [acesso em 29 set. 2018]. Disponível em: www.uil.unesco.org

13. United Nations, Secretary-General. Report of the high level panel of eminent persons on the Post2015 Development Agenda (UN, 2013). Report of the Global Thematic Consultation on Education in the Post-2015 Development Agenda. New York: UNESCO-UNICEF; 2013.

14. World Health Organisation, Regional Office for Europe. Health 2020: Education and Health through the Life-course. Copenhagen; 2015.

15. Global Commission on the Future of Work. Work for a Brighter Future. Geneva: International Labour Organization; 2019.

16. Ramey VA, Francis N. A Century of work and leisure. Am Econ J Macroecon. 2009;1(2):189-224.

17. Kohli M. The Institutionalization of the lifecourse: looking back to look ahead. Res Hum Dev. 2007;4(3-4):253-71

18. Kluge FA, Zagheni E, Loichinger E, Vogt T. The Advantages of Demographic Change after the wave: fewer and older, but healthier, greener and more productive. Plos ONE. 2014;9(9):e108501 [11p.].

19. Institute of Health Equity. Local Action on Health Inequalities: Adult Learning Services. Waterloo Road: Public Health England; 2014. (Health Equity Evidence Review, 4). 
20. Field J. Life-long learning, welfare and mental wellbeing into older age: trends and policies in europe. In: Boulton-Lewis G, Tam M, Editors. Active Ageing, Active Learning. London: Springer Netherlands; 2012. p.11-2.

21. Organization for Economic Co-operation and Development. Automation and Independent Work in a Digital Economy, Policy Brief on the Future of Work. Paris: OECD; 2016.

22. United States. Departament of Commerce. Census Bureau. Maryland; 2015.
23. International Longevity Centre Brazil. Toward age-friendly design. Rio de Janeiro: ILC-BR Publications; 2016.

24. Bloom D, Chatterji S, Kowal P, Lloyd-Sherlock P, Mckee M, Rechel B, et al. Macroeconomic implications of population ageing and selected policy responses. Lancet. 2014;285(9968):649-57.

25. International Longevity Centre Brazil. Building resilience throughout our increasingly longer lives. ILC-BR Publications, 2017.

26. Organization for Economic Co-operation and Development. Education at a Glance: OECD Indicators 2018. Paris: OECD; 2018. 